\title{
Lighting of public spaces at nodal points
}

\author{
Rafat Graczyk ${ }^{1, *}$, Artur Nawrowski ${ }^{1}$, and Ryszard Nawrowski ${ }^{1}$ \\ ${ }^{1}$ Institute of Elecrtical Engineering, Poznan University of Technology, 60-965 Poznan, ul. Piotrowo 3a, Poland
}

\begin{abstract}
The publication deals with the issue of lighting public spaces in small towns near the impact of a large urban agglomeration. Indicated the possibility of shaping the illumination of the space based on nodal points. The illumination of a representative example of the city of Lubon located in the Greater Poland was analyzed. The work summarizes the conclusions in the field of lighting and urban problems in the area of shaping public spaces, including nodal points.
\end{abstract}

\section{Introduction}

\subsection{History and location of the city of Lubon}

The city of Lubon within the current administrative borders are three villages connected with each other Żabikowo, Luboń, and Lasek, which in 1954 was incorporated into one administrative organism under the name of the dominant village with the prevalent industrial function of Lubon. It borders on the north with the capital city of Poznan. After 2000, along the northern boundary of the city, the construction of an important communication route in Poland - the A2 highway [1].

\subsection{Nodal points between Poznan and Lubon city}

The term node is understood as a designated part of the space that is an intersection of an important communication route with an administrative border between two cities (Fig.1).



Fig. 1. Administrative boundary between Poznan and Lubon, with the selection of nodal points and illumination of the sacral building (yellow selection) [1,2].
Along the highway section passing through northern Lubon and southern Poznan there are five nodal points [1] (Fig. 1, Fig. 2).

\section{Lighting of public spaces of small cities on the example of Lubon city}

Public lighting in Lubon consists of: road lighting (68\%), illumination of architectural objects (9\%), lighting of squares and parkings (9\%), lighting of green areas (7\%), advertising lighting (4\%) and others (3\%) [1].

The distribution of lighting in the public space of Lubon is uneven. Within the administrative boundaries, a large part of the lighting is located on the outskirts of the city. The highway acts as a "buffer" and a connector between cities. Lighting is particularly important in nodal points [1].



Fig. 2. View of A2 highway from Papal Hill in Lubon (yellow selection from fig. 2) [1].

The level of lighting on the highway is determined in the European Union countries according to PN-EN 13201. These levels are also obligatory at nodal points. Highway illumination at the intersection of two cities should be subject to special protection at nodal points.

Corresponding author: artur.nawrowski@put.poznan.pl 
This means that no other lighting should be found in the road lane from the illumination of architectural objects, advertising lighting, etc [1].

On Fig. 3 authors presented negative lighting of sacral object, which influence on highway lighting also in nodal points. There are unpleasant visual impressions in four nodal points.



Fig. 3. Negative lighting of sacral object (yellow selection from fig. 2) [1].

It is important that the color of the interfering light is different from the color of the highway lighting. This situation strengthens the effect that interferes with moving along the highway. Research conducted in small towns of Greater Poland clearly indicate that this phenomenon is particularly dangerous at nodal points [1].

Observation of lighting at nodal points in Poland indicates that negative phenomena are also visible on the A4 highway of the Silesian agglomeration, the A2 highway in the Warsaw, Lodz and Poznan agglomerations. This problem affects most of these places in Europe.

There are regulations specifying the distances of buildings from local, national and high-speed roads. There are no guidelines regarding the installation of light spots and the invasion of this lighting in the road lane [1].

\section{Urban and lighting issues in the area of range public spaces including nodal points}

Single lighting activities in the city space are of an ad hoc character and are primarily associated with the lighting of public roads. They dictate norms PN-EN 13201. Illumination activities aimed at pay attention of the viewer observing the architectural object at night can not affect the lighting of public roads, especially at nodal points.

There are no rules nowadays on influence of obtrusive light on normalized highway lighting.

It has not presented guidelines allowing implemented in the urban agglomeration areas of lighting a coherent policy, taking into account, for example nodal points.
There are no recommendations for electric lighting on a scale of agglomeration is also the direct cause of the inconsistency of space - the lighting of modern European cities.

\section{Conclusions}

Changes in Poland since 2000 in the aspect of sports and road infrastructure, the situation on the labor market, have improved the image of the largest Polish agglomerations. There is a change in the image of entire urban areas, districts and, finally, the most prestigious parcels of cities. Despite the socio-economic transformations of the cities of the Poznań agglomeration, preserved in their many historical architectural forms such as: urban quarters with buildings from the 19th century, industrial buildings, which are an element of the historical heritage often distinguished in the building's original form [1].

The bonding element these old forms with modern engineering structures, such as motorways, bridges and viaducts, is artificial light [1].

Nodal points created in this way will become elements that crystallize and identify the tissue of a small city. The protection of nodal points is a matter of road users' safety and proper functioning of this part of an important transport node.

The most important conclusions from the conducted research is the fact that there is a need and possibility to plan lighting of public public spaces. This is possible thanks to the photometric and colorimetric parameters of the light. Such actions they will contribute into an improvement in the image of these spaces and an increase in the sense of security at night [1].

\section{References}

1. Field Research of small towns in Greater Poland 2014-2018, Division of Urban Planning, Poznan University of Technology

2. Source: https://geoportal.gov.pl (author's preparation, 2019) 